Portland State University

PDXScholar

1976

\title{
An Examination of the Interrelationship Between \\ Caregiver Behaviors, Infant Temperament and Perceptual-Cognitive Development
}

Anita E. Stauffer

Portland State University

Follow this and additional works at: https://pdxscholar.library.pdx.edu/open_access_etds

Part of the Child Psychology Commons

Let us know how access to this document benefits you.

\section{Recommended Citation}

Stauffer, Anita E., "An Examination of the Interrelationship Between Caregiver Behaviors, Infant Temperament and Perceptual-Cognitive Development" (1976). Dissertations and Theses. Paper 2412. https://doi.org/10.15760/etd.2409

This Thesis is brought to you for free and open access. It has been accepted for inclusion in Dissertations and Theses by an authorized administrator of PDXScholar. For more information, please contact pdxscholar@pdx.edu. 
AN ABSTRACT OF THE THESIS OF Anita E. Stauffer for the Master of Arts in Psychology presented November 18, 1976.

Title: An Examination of the Interrelationship Between Caregiver Behaviors, Infant Temperament and Perceptual-Cognitive Development

A PPROVED BY MEMBERS OF THE THESIS COMMITTEE:

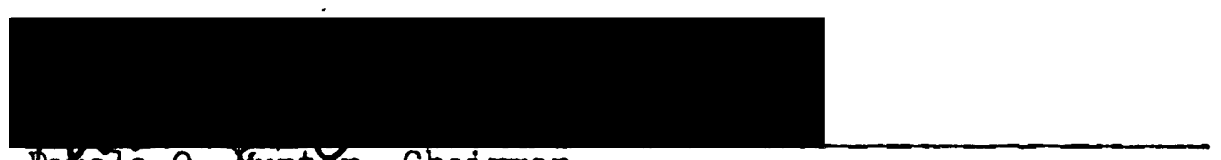
Ramela 0. Munter, Chairman
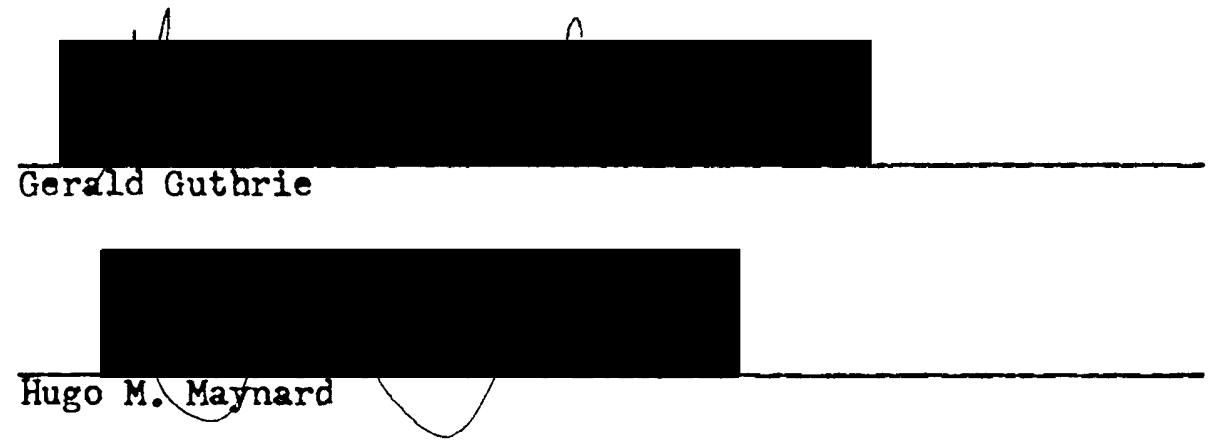

The present study extended the Lowis and Goldberg (1968) study and included the parameter of infant temperament as defined by Thomas, Cbess, Birch, Hertzig and Korn (1963). As in the Goldberg study, the index of response decrement was used as a measure of the infant's development. It was hypothesized that response decrement would be positively correlated with a high freouency of caregiver stimulation and negatively correlated with high infant intensity and activity ratings. Response decrement is the measured decrease in the amount of time an infant looks at a novel stimulus after several trials. It was computed by obsorving the infant's fixation to a single blinking light over 
four trials, and subtracting the total amount of time looking on trial four from trial one. A checklist was used to record caregiver looking, smiling, touching, holding, vocalizing and reading for 2 ten minute period. Intensity and activity scores were derived from the Survey of Temperamental Characteristics (Carey, 1970) which was completed by caregivers. Results did not confirm the hypothesis. No significant relationship between caregiver behaviors, infant activity or intensity and response decrement was discovered. Possible reasons for the non-significant results of the present study were discussed. 
AN EXAMINATION OF THE INTERRELATIONSHIP BETWEEN CAREGIVER BEHAVIORS, INEANT TEMPERAMENT AND PERCEPTUAL-COGNITIVE DEVELOPMENT

by

ANITA E. STAUFFER

A thesis submitted in partial fulfillment of the requirements for the degree of

MASTER OF ARTS

in

PSYCHOTOGY

Portland State University

1976 
TO THE OFFICE OF GRADUATE STUDIES AND RESEARCH:

The members of the Committee approve the thesis of Anita E. Stauffer presented November 18, 1976.

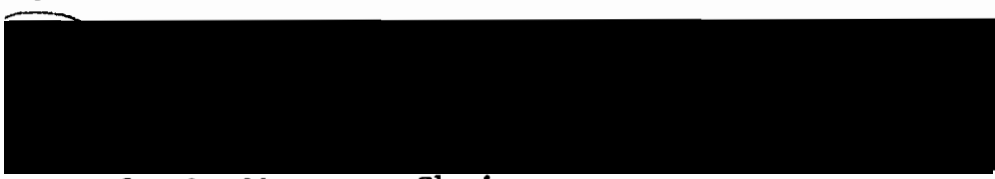

Pamela 0. Munter, Chairman

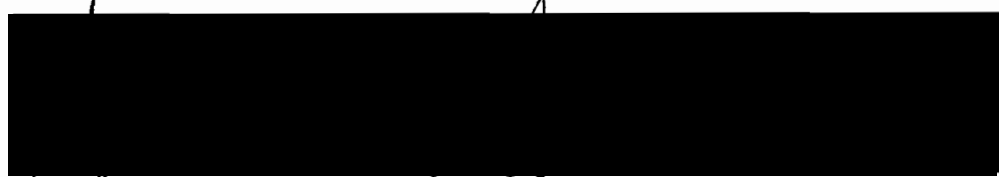

Gerald D. Guthrie

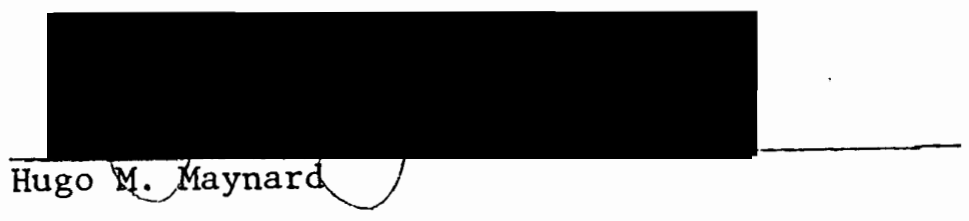

APPROVED :

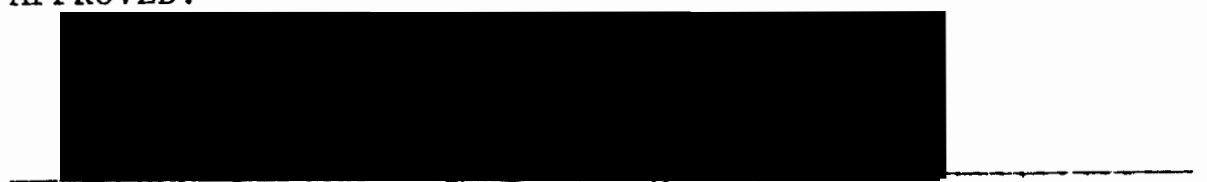

Robert"E. Jones, Hegd, Department of Psychology

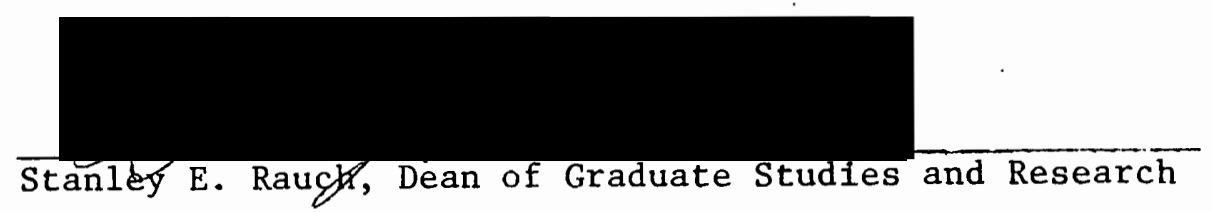


TABLE OF CONTENTS

PAGE

\section{LIST OF TABLES}

LIST OF FIGURES

$\cdot \cdot$

CHAPTER

I INTRODUCTION • • • • • • • • • • • •

1

II REVIEW OF THE LITERATURE • • • • . . . 4

III DESCRIPTION OF THE PRESENT STUDY • • . 11

IV METHODS . . . . . . . . . . . . . 13

Subjects • . • . . . . . . . . . 13

Apparatus and Equipment . . . . 13

Procedure . . . . . . . . . . 16

Questionnaire

Experimental Session

Controlled Naturalistic Setting

V RESULTS $\quad$ • . . . . . . . . . . . . . . . 20

VI DISCUSSION • • . • . • • • • • • • • 24

REFERENCES . • • • • . . . . . . • • . . . 28

APPENDIX . • • . . . . . . . . . . . . 34 


\section{LIST OF TABLES}

TABLE

PAGE

I Means and Standard Deviations

for Temperament Categories . . . - 22

II Coefficients for the Test for the

Significance of the Difference

between Correlations of Walker

and Lev (1953) • . . . . . • • 22

III Means and Standard Deviations for

Caregiver Behaviors Observed • • • 23 


\section{LIST OF FIGURES}

TABLE

PAGE

I Arrangement of apparatus and

equipment. . . . . . . . . 15 
CHAPTER I

INTRODUCTION

Discussions of the critical aspects of the child's success in the educational system and of the dependence of such success on early reading have been numerous in the last decades. As a result, schools have invented and instituted all sorts of remedial programs for the child identified as deficient in reading ability. Unfortunately, the degree of help has not been as significant as educators or concerned parents might have hoped. The reading disabled child who has been returned to the classroom has most often remained below average in reading abilities.

We cannot entirely blame the schools for the inadequacy of remedial programs. Kaluger and Kolson (1972) cite the following three major determinants involved in the development of perceptual-conceptual processes: neural sensorimotor patterns, environmental influence and psychogenetic development. Neural sensorimotor patterns refer to the organic aspects of cognitive development. Environmental influence includes the sensory stimulation provided by the child's social and cultural (including educational) environ- 
ment, and the psychogenetic component refers to the sucioeconomic status of the home, family organization, expectations of the parents and affective influences. Although Kaluger and Kolson's semantics might be debated, the idea is widely accepted that there are both organic and functional influences in the development of pexceptual-conceptual processes. Thus, the educational environment is but one factor affecting the child's success in the early reading task.

Recognizing the importance of the early reading task, a number of researchers have sought to develop evaluation instruments and programs toward the early identification of children with potential learning problems (Keogh and Smith, 1967; Evans and Ferguson, 1974; Satz and Friel, 1974; Eaves, et al., 1974). Justification for such early identification can only be found, however, if effective programs exist for those children. Keogh and Becker, both proponents of early identification programs, cite problems of ascertaining the validity of predictive measures, and the placement of children in programs often on the basis of program availability. Rosenthal and Jacobson's (1966) study suggests another possible disadvantage to early identification: the term "selffulfilling prophecy" represents the idea that sets of expectancies may affect behavior that is later emitted. If some 
children are identified as more likely to manifest learning disabilities, perhaps this very identification will affect their subsequent behavior, because it affects the way others relate to them. Even if effective educational programming could be invented for potentially learning disabled children, the availability of funds necessary to institute the programs as they were planned might be absent. Investigation must go back even farther in the child's life to examine the earliest facets of the development of perceptualconceptual processes. 
Korner (1973) did an extensive review of the literature in the capabilities of newborns. Experimental studies are cited that support the assertions that newborns are able to visually fixate on objects, respond to auditory stimuli, and demonstrate skillful hand-to-mouth coordination and the rudiments of eye-hand coordination. Research, to a certain extent, indicates that the neonate is capable of learning. The idea of the neonate as a piece of undifferentiated protoplasm with few abilities is inaccurate.

Recent research also suggests that individual infants differ at birth; the degree of their capabilities and the type of behavioral style vary. What the infant brings to the child-parent interaction must not be overlooked. To summarize briefly, research with neonates and young infants indicates that individual differences are present from birth in the following behaviors: visual fixation and pursuit (Greeman, 1968; Barten, Birns, and Ronch, 1971; Boyd, 1973). sucking (Korner, 1972), auditory abilities (Bridger, 1961), sensory threshold levels (Korner, 1971), frequency and duration of crying (Moss and Robson, 1968), soothability (Birns, 
Blank and Bridger, 1966), cuddling behavior (Schaeffer and Emerson, 1964), and temperament (Thomas, Chess, Birch ancl Hertzig, 1963). Thomas et al. define temperament as the emotional reactivity or behavioral style displayed by the infant in the early months. They describe differential temperament in terms of nine categories of reactivity: activity, rhythmicity, approach-withdrawal, adaptability, intensity, threshold, mood, distractibility and persistence. Thus, the infant is not only a receptor of whatever his environment offers. He, from birth, helps shape his environment by cueing different responses in his parents. For example, the infant who makes his body rigid when held closely by a parent will probably be held less and may as a consequence receive less tactile, visual and auditory stimulation.

Although the importance of the maternal-infant relationship has long been accepted, knowledge of the infant's differences and early abilities places perhaps more and different importance on the caregiving role. Traditionally, care of infants has been delegated to the female making the maternal role a subject of much research. Presently, the individual giving primary care is not necessarily the mother or female. Therefore, we will refer to this individual as the primary caregiver. So, in addition to the caregiver 
role in the infant's emotional development, the caregiver is now also cited as the primary source for a large part of tarly experience and thus for cognitive development. Although it cannot be denied that cognitive development is affected by genetic endowment, some aspects of such development are iniluenced by environment (Hunt, 1963). The timetable of development can be accelerated, decelerated or even stopped by environmental events (Greenberg, 1969).

Both Lewis and Goldberg (1968) and Brown and Ottinger (1970) emphasize the positive effects of environmental stimulation to cognitive development in infants. Cited often in the literature, Lewis and Goldberg (1968) used the measure of response decrement to repeated signals to assess the level of perceptual cognitive development in infants. Response decrement is the measured decrease in the amount of time an infant looks at a novel stimulus after several trials. Use of the measure is based on the work of Sokolov (1963) and on the idea that cortical changes are a function of the build-up of expectations or models. According to Sokolov's neuronal model, if a presented stimulus corresponds to an already existing cortical model, a type of negative feedback occurs, and response is rapid or absent. If the stimulus does not correspond with the existing model or if the model is not yet well 
developed, excitation and an orienting reflex takes place. The more rapidly the model is acquired, the briefer the amoun: of time the infant will fixate each time he sees the signal repeated.

Lewis and Goldberg (1968) reviewed the research that indicates that rapid response decrement to repeated signals in infancy is positively related to measures of cognitive capacity such as preschool IQ and performance on concept formation tasks. Assuming that response decrement might be used as a measure of model acquisition reflecting perceptual cognitive development, they used the index to judge the effect of maternal behavior on the infant's cognitive development. Results of the study positively correlated the infant's response decrement with various maternal behaviors. The more the mother provided stimulation, the less the infant attended to a repeated signal.

Testing neonates rather than infants, Brown and ottinger (1970) also concluded that environmental stimulation accelerates perceptual cognitive development. Brown and Ottinger (1970) tested neonates for visual attentiveness to a series of patterns 12-30 hours after birth. Experimental groups were exposed to 140 minutes a day of supplementary experience including holding, rubbing, rocking, mother talk and various 
types of visual stimulation. Results showed that experimental babies looked at a complex visual stimulus significantly longer than did control babies.

The abilities of the neonate and infant, the individual differences between them, the importance of stimulation, of the parental bond - all of these have been ascertained and seem crucial to the child's development. However, can we separate parent and child effects in order to discover the ingredients of optimal development? If infants have individual levels of ability and varying temperaments, can manipulating only environmental variables yield information that is truly valid?

Students of animal behavior have been much more convinced of the offspring effects on parents than researchers of the human parent-child interaction. Beach and Jaynes (1956), for example, manipulated appearance and behavior of rat pups and identified visual, olfactory, tactile and thermal cues that evoked maternal retrieving for individual pups. Bell (1968) suggests that if variations in the behavior of offspring affect animal parents, even greater effects might be expected on human parents; human parental behavior, it seems, would be even more susceptible to more complex classes of stimuli. That is, human parents would be even 
more likely to respond to their infants differentially.

Several researchers (Bell, 1974; Brazelton, Koslowski and Main, 1974; Korner, 1974; Lewis and Painter, 1974; Rosenblum, 1974) argue that the study of behavior elements of either caregiver or child alone is insufficient for discovering what transpires between them. They insist that research directed toward the caregiver-infant dyad must take an interactional approach. The present socialization model, emphasizing the parental effects on the child is too limiting. We cannot assume that caregiver responses are not differentially cued by individual infants. The infant who is doing anything but sleeping may be cueing caregiver behavior. Some caregiver behaviors, such as burping or holding, often viewed as behaviors emitted by the caregiver, may instead by elicited by the infant through contextual cues. Research needs to consider the interaction of parent and child effects.

Dr. Lonis Liverman, speaking at the University of California Conference on the Early Identification of Children With Potential Learning Problems has suggested that, "There is a definite interrelationship and interpendence of mother and child, mothering style, infant disposition, learning behavior and school functioning" (Keogh, 1970, p. 357). Although there are assessments of individual differences in infancy, little 
is presently known about their stability, their relevance for later development or their interaction with environmental variables (Boyd, 1973). Although research points toward the discovery of more information about the interrelationship that Liverman suggests, most of the work is still speculative at this time. 
DESCRIPTION OF THE PRESENT STUDY

The present study sought to extend the Lewis and Goldberg (1968) study and to include the parameter of infant temperament as defined by Thomas et al. (1963). As in the Goldberg study, the index of response decrement was used as a measure of the infant's development.

It was hypothesized that response decrement would be positively correlated with a high frequency of caregiver stimulation and negatively correlated with intensity and activity ratings. Activity level was defined as the amount of physical activity during sleep, feeding, play, dressing, etc., and intensity of response was defined as the energy content of responses regardless of their quality (Carey, 1972).

Results of the Lewis and Goldberg (1968) study positiveIy correlated the infant's response decrement with the amount the mother looked at or smiled at the infant, with the amount of touching the mother exhibited, and with the amount of holding exhibited during the experiment. Evidence for the potential importance of infant activity and intensity comes from the studies of Shaefer and Bayley (1963) and Bell, Weller and 
Waldrop (1971). Shaefer and Bayley (1963) reported a negative correlation between activity at 10-12 months of age and ittentiveness in boys at 27-96 months of age. Bell, Weller and Waldrop (1971), similarly, reported a negative correlation between neonatal activity and response intensity, and attentiveness to auditory and visual stimuli in the preschool period. The present study, then was designed to investigate the interacting effects of environmental stimulation and infant temperament on cognitive development. 
CHAPTER IV

METHODS

\section{Subjects}

The sample consisted of 21 normal, full-term, white infants, 11 females and 10 males. They were between the ages of 5 and 8 months and were born into middle class families who lived in the Portland metropolitan area. All of the infants came from intact families where the mother was the primary caregiver. The parents had all completed high school; $66 \%$ of the mothers and $75 \%$ of the fathers had completed college. Thirteen of the infants were firstborn. The sample was obtained through students at the university and acquaintances of the experimenter who knew of infants in the proper age range.

\section{Apparatus and Equipment}

The experimental space was the Portland State University Psychology Clinic playroom. It was a 10'x 20' we11illuminated room with one way vision windows lining one side of the room. An adjoining observation room contained audio equipment.

The experimental apparatus was in a corner and was 
14

further enclosed by a partition. Briefly, it consisted of a light mounted on a large plywood barrier and programmed to blink once every other second for 30 seconds for four trials, a seat for the infant, and an electronic counter. The seat was placed 18 inches from the light. Plywood and walls were painted off-white. A small hole was drilled below the light in the plywood barrier so that the experimenter could stand behind the barrier and observe and time the infants' fixLion to the repeated signal (see Figure 1). 


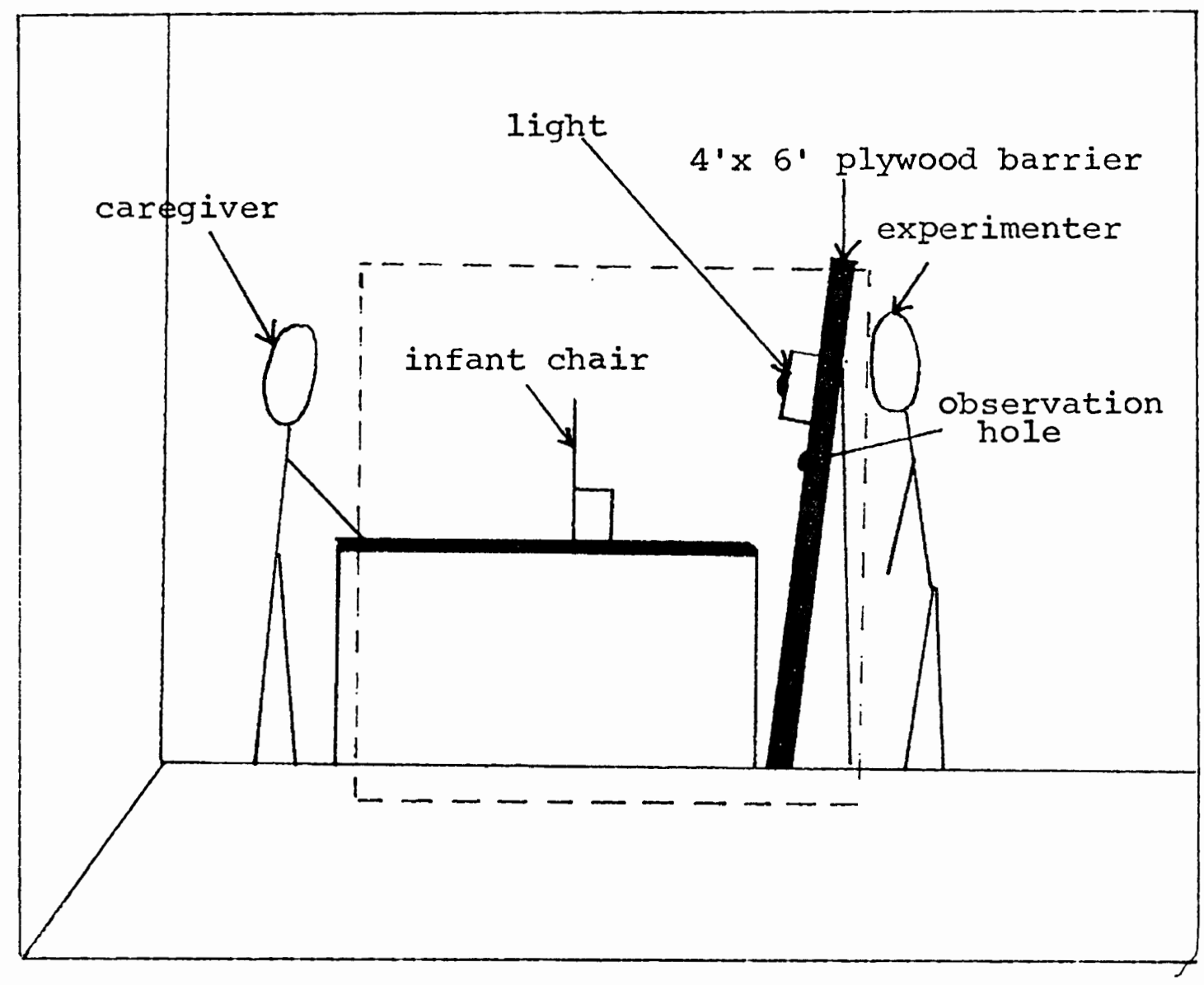

Fiqure 1. Arrangement of apparatus and equipment. Dotted lines indicate position of opaque partition. 


\section{Procedure}

Questionnaire. Prior to the date of the experimental session, W. B. Carey's Survey of Temperamental Characteristics wa: sent to the caregiver with a cover letter (see Appendix A for complete derivation), and with the request that she complete it and send it to the experimenter in an enclosed envelope. All questionnaires were returned to the experimenter by the date of the experimental session or earlier. The questionnaire was based on the work of Thomas et al. (1963) in the New York Longitudinal Study and was standardized on 200 4-8 month old infants. It consists of 70 multiple choice items, each with three choices, describing specific behavior of the baby. It was completed by the infant's primary caregiver and yielded a numerical rating for each of the categories of reactivity measured in the Thomas et al. (1963) study: activity, rhythmicity, adaptability, approach, threshold, intensity, mood, distractibility, persistence. Although only activity and intensity scores were utilized, use of the entire questionnaire was necessary to assure the validity of the parts. Caregivers were given feedback comparing their infants to the mean on each parameter of reactivity.

Experimental Session. When the caregiver and infant 
arrived, they were escorted to the experimental room. While the infant adjusted to the new surrounding, the function of the experimental apparatus was explained to the caregiver. The infant was then placed in the infant seat and the caregiver sat to the rear and side of the subject. The experimenter took her position behind the apparatus.

The stimulus was the single blinking light referred to previously. Each of four trials consisted of this light blinking once every other second for thirty seconds. Each time the subject oriented his or her head and eyes toward the light, the experimenter depressed a button marking the duration of the fixation. The amount of response decrement was computed by subtracting the amount of time looking on trial 4 from total fixation on trial 1 . This method of measuring response decrement was very similar to the one used by Lewis and Goldberg (1968).

Controlled Naturalistic Setting. After the experimental session, the experimenter explained that she wanted to observe a sample of the infant's behavior without the interference of or stimulation of strangers in the environment for ten minutes. A chair was offered to the caregiver and current magazines and coffee on a table beside the chair were pointed out. Toys in the playroom were 
accessible to the caregiver. The caregiver was asked to place the infant in the infant seat, which was now next to the chair provided for the caregiver, at least to begin the observation. A similar procedure was employed by Lewis and Goldberg so that the caregiver could more easily avoid interaction with the infant if she wished to. Lewis and Goldberg (1968) explained that this type of procedure represented an attempt to produce a wider distribution in the caregiver's response to the infant. The experimenter then left the playroom.

Every ten seconds for ten minutes, the experimenter and an assistant recorded the occurrence of caregiver looking, smiling, touching, holding, vocalizing and reading, and infant vocalizing, crying, eyes open and eyes closed. A checklist was utilized for the event sampling procedure (see Appendix B for complete derivation).

Infant vocalization referred to any audible sound made during any ten second interval. Eyes open was recorded if the infant's eyelids were open and eyes shut was recorded if the eyelids were shut for at least three consecutive seconds during any ten second interval. Caregiver looking was defined as a visual orientation toward the infant and a smile was a simultaneous retraction of the corners of the 
mouth with or without accompanying vocalization. Holding was recorded if the caregiver provided total support o1 the infant with the body for at least five consecutive seconds; touching was any type of direct bodily contact with the child other than holding. Reading was checked if the caregiver oriented the head toward a magazine, book or other written material. To vocalize was to make an audible sound. 


\section{CHAPTER V}

\section{RESULTS}

The data indicate no significant relationship between caregiver behaviors, infant activity or intensity, and response decrement. A multiple regression analysis was performed naming response decrement as the dependent variable and infant sex, age activity, intensity and caregiver looking, smiling, touching, holding, reading and vocalizing as independent variables. The $F$ value of 1.4376 with 20 degrees of freedom was not found to be significant.

Correlation coefficients were also computed for predictors and criterion separately for subgroups of high and low activity and high and low intensity. Subjects were assigned to the high activity subgroup if scores were above the median score of .50 , and to the high intensity subgroup if scores were above the median score of 1.18 . If scores were below the medians, subjects were assigned to low activity or intensity groups. Activity and intensity scores were derived through the use of the Survey of Temperamental Characteristics by William B. Carey (1970). Means and standard deviations for both temperament categories are shown in Table I. Carey's (1972) statistics computed on his stand- 
ardization group for the questionnaire ase included for comparison.

A Test for the Significance of the Difference Between Correlations (Walker and Lev, 1953) was performed on the coefficients shown in Table II. All differences were statistically non-significant. The data did not demonstrate that response decrement was significantly moderated by differences in caregiver stimulation, or infant activity or intensity.

The present study did not replicate the statistically significant results of the Lewis and Goldberg (1968) study, positively correlating response decrement and caregiver looking, smiling, touching and holding. Means and standard deviations for the caregiver behaviors observed in the present study are included in Table III. Inter-observer reliability coefficients in the present study were all greater than .95 . 
TABLE I

MEANS AND STANDARD DEVIATIONS FOR

TEMPERAMENT CATEGORIES

\begin{tabular}{|l|c|c|c|c|}
\hline & \multicolumn{2}{|c|}{ The present study } & \multicolumn{2}{c|}{ Carey, 1972} \\
\hline & Means & s.d. & Means & s.d. \\
\hline Activity & 0.49 & 0.26 & 0.49 & 0.31 \\
\hline Intensity & 1.17 & 0.34 & 1.06 & 0.31 \\
\hline
\end{tabular}

TABLE II

COEFFICIENTS FOR THE TEST FOR THE SIGNIFICANCE

OF THE DIFFERENCE BETWEEN CORRELATIONS

OF WALKER AND LEV (1953)

\begin{tabular}{|l|c|c|c|c|}
\hline & $\begin{array}{c}\text { High } \\
\text { Activity }\end{array}$ & $\begin{array}{c}\text { Low } \\
\text { Activity }\end{array}$ & $\begin{array}{c}\text { High } \\
\text { Intensity }\end{array}$ & $\begin{array}{c}\text { Low } \\
\text { Intensity }\end{array}$ \\
\hline Look & -.64 & -.28 & -.22 & .15 \\
\hline Smile & -.27 & .05 & .05 & -.52 \\
\hline Touch & -.28 & -.04 & .18 & -.67 \\
\hline Hold & .25 & -.25 & -.09 & .37 \\
\hline Read & -.67 & -.28 & -.22 & .04 \\
\hline Vocalize & -.02 & -.38 & -.42 & .54 \\
\hline
\end{tabular}


TABLE III

MEANS AND STANDARD DEVIATIONS FOR

CAREGIVER BEHAVIORS OBSERVED

\begin{tabular}{|l|c|c|}
\hline & $\begin{array}{c}\text { Mean or average \% } \\
\text { of time spent }\end{array}$ & Standard Deviation \\
\hline Look & .57 & .23 \\
\hline Smile & .16 & .17 \\
\hline Touch & .06 & .08 \\
\hline Hold & .11 & .19 \\
\hline Read & .31 & .25 \\
\hline Vocalize & .16 & .13 \\
\hline
\end{tabular}


CHAPTER VI

\section{DISCUSSION}

There are various factors that may have contributed to the non-significant results of the present study. First, the sampling of caregiver and infant behavior was brief and was not in a natural environment. Although it would be impossible to measure how much knowledge of observation affects caregiver or infant behavior, observation in the home might at least eliminate the variable of a foreign environment. It is also possible that a longer observation period might have yielded more valid data. The Lewis and Goldberg (1968) study utilized a similar controlled naturalistic environment for observation, but the observation period was one hour rather than ten minutes.

A second intervening variable might be found in the sample. Sixty-nine percent of the caregiver participants were college educated, various others had partial college training and all valued the research process enough to make a trip to Portland state University with their infants, and in many cases to arrange for babysitters for their other children. Although this type of sample is characteristic 
of that of many research studies, it may have been too homogeneous a group to observe important differences that exist in the general population.

The present study might also have been improved by using a different measure of infant activity and intensity. Although the Carey (1972) questionnaire is a reliable one that asks for clear behavioral information, it is a selfreport instrument, and biases cannot be eliminated. The Thomas et al. (1963) study used a complex and lengthy interview and observation period to access temperament. Both the Carey (1972) and the Thomas et al. (1963) methods were tested on the same subjects and results were significantly similar (Carey, 1972). This reliability test on the Carey instrument, however, involved only a small sample of subjects. The present study might be improved by investigating other than a self-report measure on infant activity and intensity. Finally, the present study might be improved by controlling more carefully for infant age. Although rapid response decrement did not correlate positively with infant age in this study, and age was partialled out in the final analysis, it cannot be definitely said that age did not interfere in the results. Because of the rapid rate of development during the first year, it is probably preferable to study a 
sample of same age infants. Lewis and Goldberg (1968) studied same age infants.

This study has not added to the body of knowledge that might help define the ingredients of optimal perceptual cognitive development in the infant. There are several hypotheses that attempt to explain such optimal development. The first, a linear hypothesis, represented by the Lewis and Goldberg (1968) study, suggests that the more caregiver stimulation an infant receives, the better his perceptual cognitive development will be. This hypothesis was not supported by the present study. In fact, the correlations in the present study, though non-significant seemed to suggest that the infants who received the most stimulation did more poorly on the response decrement measure.

The second hypothesis suggests that an interaction of caregiver stimulation and temperamental characteristics determines the course of perceptual cognitive development. Although this relationship was not found to be statistically significant in the present study, enough research has been done to suggest that such a relationship exists even though it has not been defined.

A third nonlinear hypothesis emphasizes the rhythm of 
infant caregiver interaction rather than the number of interactions. Generated in the Harvard Preschool Project, clis hypothesis suggests that there is an optimal number and type of caregiver-infant interactions, some initiated by the caregiver and others cued by the infant (White, 1973). Perhaps a hypothesis combining the interaction ideas of the present study and the non-linear idea of the Harvard project should be tested in a future study. 
REFERENCES

Barten, S., Birns B. \& Ronch J. Individual differences in the visual pursuit behavior of neonates. Child Development, 1971, 2. 313-319.

Beach, F. A. \& Jaynes, J. Studies of maternal retrieving in rats. II. Sensory cues involved in lactating females' response to her young. Behaviour, 1956, 10, 104-125.

Bell, R. Q. A reinterpretation of the direction of effects in studies of socialization. Psychology Review, 1968, 75. $81-95$.

Bell, R. Q. Contributions of human infants to caregiving and social interaction. In $M$. Lewis (Ed.), Effect of the infant on its caregiver. New York: John Wiley \& Sons, 1974 .

Be11, R. Q.. Weller, G. M. and Waldrop, M. F. Newborn and preschooler: organization of behavior and relations between periods. Monograph of the society for Research in Child Development, 1971, 36, (1-2, Serial No. 142).

Birns, B., Bland M. \& Bridger, W. H. The effectiveness of various soothing techniques on human neonates. Psychosomatic Medicine, 1966, 28, 316-322.

Brown, D. \& Ottinger, D. R. The perceptual basis of developing reading skill. Washington, D. C.: Office of Education, Bureau of Research, 1970. (ERIC Document Reproduction Service No. 050927)

Belmont, Ira. Requirements of the early reading task. Perceptual and Motor: Ski1ls, 1974, 38, 527-537.

Boyd, E. The study of individual differences in infancy and early childhood. Journal of Research and Development in Education. 1973 (Spr), 6 (3), 14-24. 
Brazelton, T. B., Koslowski, B. and Main, M. The origins of reciprocity; the early mother-infant interactio: . In M. Lewis (Ed.), Effect of the infant on its care iver. New York: John Wiley \& Sons, 1974.

Carey, W. B. A simplified method for measuring infant temperament. Journal of Pediatrics, 1970, 77, 188.

Carey, W. B. Clinical applications of infant temperament measurements. Journal of Pediatrics, 1972, 81,

Carey, W. B. Measurement of infant temperament in pediatric practice. In J. C. Westman (Ed.), Individual differences in children, New York: John Wiley \& Sons, 1973.

Chess, S. and Thomas, A. Temperament in the normal infant. In J. C. Westman (Ed.), Individual differences in children, New York: John Wiley \& Sons, 1973.

DeHirsch, K. \& Jansky, J. Early prediction of reading disability. In Keeney, A. \& Keeney, V. (Eds.), Dyslexia: diagnosis and treatment of reading disorders, saint Louis: C. V. Mosby Company, 1964.

Eaves, I. C., Kendall, D. C. \& Crichton, J. U. The early identification of learning disabilities: A follow-up study. Journal of Learning Disabilities, 1974, 7, 632-638.

Escalona, S. K. The roots of individuality. Chicago: Aldine Publishing Co., 1968.

Evans, R. \& Ferguson, N. Screening school entrants. AEP Journal, $3,2-9$.

Freeman, M. A comparative analysis of patterns of attitudes among mothers of children with learning disabilities and mothers of children who are achieving normally. Dissertation Abstracts International. 1971, 31, 5125.

Greenberg, N. H. Atypical behavior during infancy: infant development in relation to the behavior and personality of the mother. In Anthony, E. \& Koupernik, C. (Eds.), Child in his family, New York: John Wiley \& Sons, Inc., 1970 . 
Greenberg, N. H. \& Hurley, J. The maternal personalit. inventory: An objective instrument for assessing pirrsonality attributes in relation to maternal behavior and infant development. In J. Helmuth (Ed.), Exceptional infant: II. Studies in abnormalities, New York: Brunner/Maze1, 1971.

Hunt, J. MCV. The epigenesis of intrinsic motivation and the stimulation of early cognitive learning. Paper presented at Symposium on "Stimulation of Early Cognitive Learning", American Psychological Association, Philadelphia, Aug., 1963.

Kaluger, G. \& Kolson, C. Reading and learning disabilities. Columbus, Ohio: Charles E. Merrill Publishing Co., 1972 .

Kappelman, M. Prenatal and perinatal factors which influence learning. In Hellmuth, J. (Ed.), Exceptional infant: II. Studies in abnormalities, New York: Brunner/Mazel, 1971.

Kasdon, L. M. Causes of reading difficulties. In Durr, W. K. (Ed.), Reading difficulties: diagnosis, correction and remediation. Newark, Del.: International Reading Association, Inc. 1970.

Keogh, B. K. Early identification of children with potential learning problems. Journal of Special Education, 1970, 4, 307-365. (Monograph)

Keogh, B. K. \& Becker, I. D. Early detention of learning problems: questions, cautions, and guidelines. Exceptional Children, 1973, 40, 5-11.

Korner, A. F. Early stimulation and maternal care as related to infant capabilities and individual differences. Early Child Development \& Care, 1973, 2, 307-327.

Korner, A. F. The effect of the infant's state, level of arousal, sex and ontogenetic stage on the caregiver. In M. Lewis (Ed.), Effect of the infant on its careqiver. New York: John Wiley \& Sons, 1974. 
Korner, A. F. Individual differences at bixth: implications for early experience and later development. In $\mathrm{J}$. Westman, Individual differences in children. New York: John Wiley \&Sons, 1973.

Lewis, M., Goldberg, S \& Campbell, M. A developmental study of information processing within the first three years of life: Response decrement to a redundant signal. Monographs of the Society for Research in Child Development, 1969, 34 (9, Serial No. 133).

Lewis, M. \& Goldberg, S. Perceptual-Cognitive Development in Infancy: A Generalized Expectancy Model as a Function of the Mother-Infant Interaction. Yellow Springs, Ohio: Fels Research Institute, 1968. (ERIC Document Reproduction Service No. ED 024 470).

Lewis, M. and Painter, S. An interactional approach to the mother-infant dyad. In M. Lewis (Ed.), Effect of the Infant on its Caregiver. New York: John Wiley \& Sons, 1974 .

Iipsitt, I. Learning in the first year of life. In Lipsitt, I. and Spiker, C. (Eds.), Advance in Child Development and Behavior, 1968, 147-181.

McCall, R. B. and Kagan, J. S. Individual differences in infant's distribution of attention to stimulus discrepancy. Developmental Psychology, 1972, 2. 90-98.

McCall, R. B. and Melson, W. H. Attention in infants as a function of the magnitude of discrepancy and habituation rate. Psychonomic Science, 1969, 17, 317-319.

McCarthy, Dorthea. Factors that influence lanquage growth. Champaign, Ill.: National Conference on Research in English, 1953. (ERIC Document Reproduction Service No. ED 0893591)

Rosenblum, I. A. Developmental changes in compensatory dyadic response in mother and infant monkeys. In $M$. Lewis (Ed.), Effect of the infant on its caregiver, New York: John Wiley \& Sons, 1974. 
Rosenthal, R. \& Jacobson, I. Teachers' expectancies: Determinants of pupils' IQ gains. Psychological Reponts, 1966, 19, 115-118.

Satz, P. \& Friel, J. Some predictive antecedents of specific disability: A preliminary two-year follow-up. Journa I_of Learning Disabilities, 1974, I, 437-444.

Shaefer, E. S. and Bayley, N. Maternal behavior, child behavior, child behavior, and their intercorrelations from infancy through adolescence. Monographs of the Society for Research in Child Development, 1963, 28 (3, Serial No. 87).

Schaffer, H. \& Emerson, P. Patterns of response to physical contact in early human development. Jourmal of Child Psychology and Psychiatry, 1964, 5, 1-13.

Sokolov, Ye. N. Perception and the conditioned reflex. New York: Macmillan Co. (S.W. Waydenfeld, Trans.), 1963.

Stern, D. N. Mother and infant at play: the dyadic interaction involving facial, vocal, and gaze behaviors. In M. Lewis (Ed.), Effect of the Infant on its Caregiver. New York: John Wiley \& Sons, 1974.

Stone, I. J., Smith, H. T. \& Murphy, I. B. Competent Infant. New York:Basic Books, Inc., 1973.

Thomas, A., Chess, S., Birch, H.G., Hertzig, M.E. and Korn, S. Behavioral individuality in early childhood. New York: Guilford University Press, 1963.

Walker, H. M. \& Lev, J. Statistical Inference. New York: Henry Holt \& Co., 1953, 255-6.

Wetter, J. Relation of parent attitude to learning disorder. Dissertation Abstracts Internationa1, 1971, 31. 5893 .

White, B. I. Experience and environment: major influences on the development of the young child. Englewood Cliffs, N. J.: Prentice Hall, 1973. 
Wyden, B. W. The difficult baby is born that way. In R. A. Miner and S. Friedman (Eds.), Annual editions: R adings in human development, Guilford, Conn.: Dushkin Publishing Group, 1975. 
APPENDIX A

LETTER SENT TO CAREGIVERS

\author{
Anita E. Stauffer \\ Department of Psychology \\ Portland State University \\ Box 751 \\ Portland, OR
}

Dear

Thank you very much for agreeing to participate in a research project studying temperamental differences in babies. Your contribution is certainly appreciated and you $c$ an learn something about your baby in the process.

Most parents know that babies differ in the style or quality of their reactions right from the beginning, quite apart from the extent of their accomplishments. Little research, however, has been done to measure these differences and work out their significances.

The purpose of the enclosed questionnaire is to determine the general pattern of your baby's reaction to his or her environment by getting specific information about many areas of functioning. You will also be asked some questions about that environment and about your general impressions of the baby. Please answer the questions in order without skipping about.

The temperament questionnarie itself consists of 70 statements about the baby, each with three choices. Please circle the letter "a", "b", or " $c$ " before the choice that properly describes the baby. If none of the 3 possibilities is truly suitable, please do not circle any letter. For example, a baby may have had no illness yet. If there has been a change in the baby, the answer should be what applies more recently. There are no good and bad or right and wrong answers, only descriptions of what the baby does. It will probably take 15 to 25 minutes. 
Please return the completed questionnaire to me in the enclosed envelope. I will be looking forward to seeing rou and your baby on at in the department lobby, 317 cramer Hall. Thank you again for your participation in this project. I can share the results with you later if you are interested. If you have any further questions, please call me at 233-2717.

Sincerely,

Anita E. Stauffer 


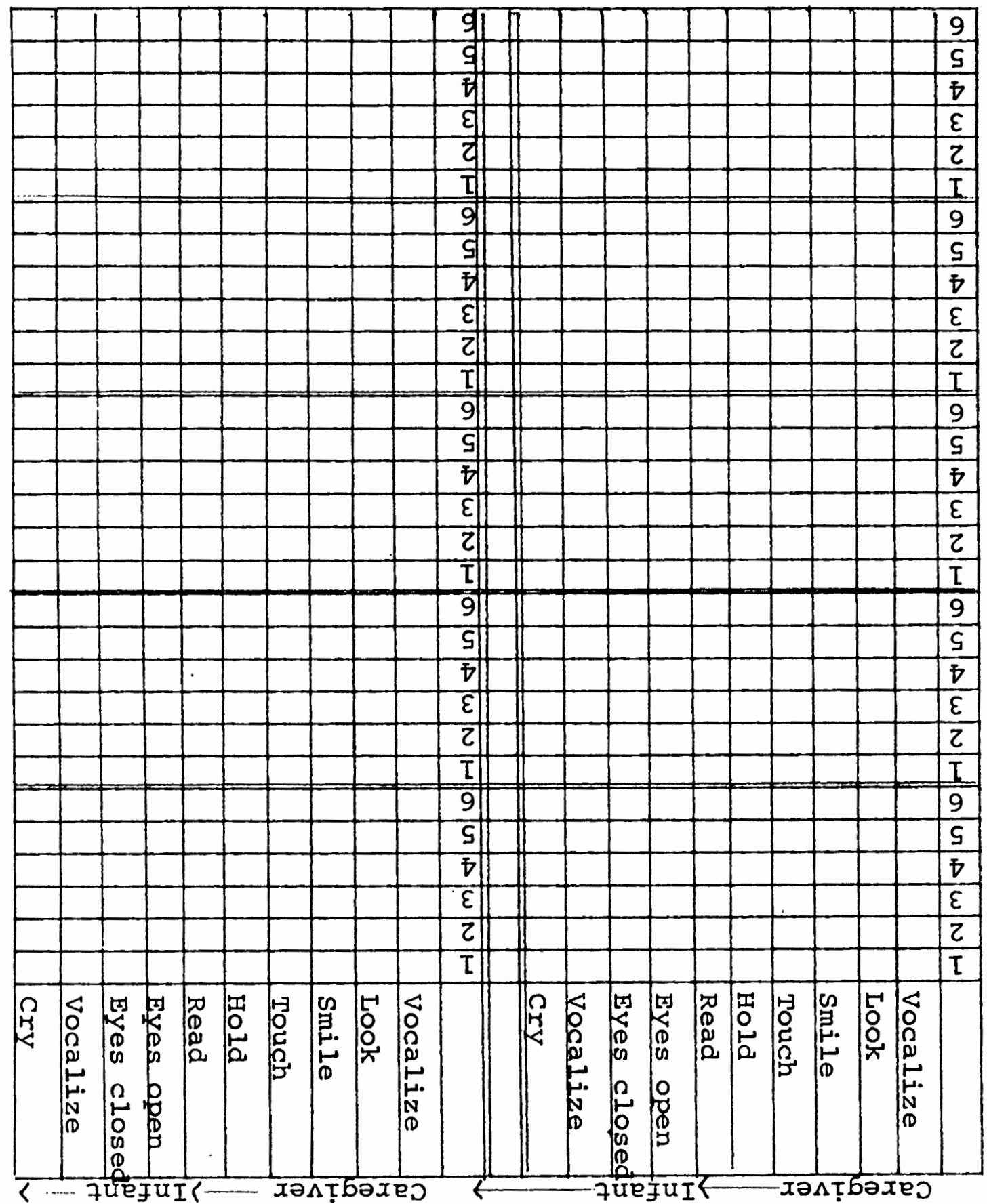

山SITYว

g XIđNGAdY 